\title{
MUSEU XUCURUS: O SILÊNCIO DO ACERVO E AS POLIFONIAS DOS SUJEITOS
}

\author{
JOSÉ ADELSON LOPES PEIXOTO ${ }^{1}$ \\ UNEAL, BRASIL
}

LARISSA FERREIRA FERRO ${ }^{2}$

UFAL, BRASIL

\begin{abstract}
RESUMO: Este artigo apresenta narrativas sobre o Museu Xucurus de História, Arte e Costumes, localizado no prédio da Igreja Nossa Senhora do Rosário, em Palmeira dos Índios, Alagoas. Apesar do nome fazer homenagem aos indigenas, os Xukuru-Kariri não se sentem representados pelo acervo. Desde a sua fundação, o museu é palco de embates entre a prefeitura, a sociedade e a diocese e com o passar dos anos, se converteu em um espaço de dualidades entre o instituído e o desejado, pois apresenta um acervo sem tratamento ou catalogação e a exposição não dialoga entre si, nem com a cultura local. Teoricamente nos amparamos em Schwarcz (2008), Clifford (1994), Chagas (2007), De L'Estoile (2011), Silva e Gordon (2011) para compreender a gênese das disputas que culminaram na tentativa de transferir o acervo para outro espaço. Metodologicamente, entrevistamos lideranças indigenas, membros do Conselho Municipal de Cultura, o Prefeito e a Secretária de Cultura para ouvir narrativas e argumentos dos principais envolvidos no imbróglio, principalmente os indígenas que nomeiam o museu e não são consultados sobre a exposição de seus artefatos.
\end{abstract}

PALAVRAS-CHAVE: Acervo. Disputas. Identidade.

ABSTRACT: This article presents narratives about the Xukurus Museum of History, Art and Customs, Located in the building of Nossa Senhora do Rosário, in Palmeira dos Índios, Alagoas. Despite the name do homaging to the natives, the Xukuru-Kariri do not feel represented by the collection. Since its foudantion, the museum is stage of clashes with the city hall, the society and the diocese, and over the years, it converted in a space of dualities between the instituted and the desired, because presents a variated collection without treatment or cataloging and the exposition does not dialogue among itself or with the local culture. Theoretically we seek support in the assumptions of Schwarcz (2008), Clifford (1994), Chagas (2007), De L'Estoile (2011), Silveira e Lima Filho (2005), Silva e Gordon (2011). To understand the genesis of the dispute that culminated in attempting to transfer the collection to another space. Methodologically, we interviewed indigenous leaders, members of the municipal council of culture, the mayor and the secretary of culture to hear narratives and arguments of the principal involved in the imbróglio, especially the natives who name the museum and are not consulted about the exposition of their artifacts.

KEYWORDS: Collection. Clashes. Identity.

\footnotetext{
${ }^{1}$ Professor Adjunto na Universidade Estadual de Alagoas. Coordenador do Grupo de Pesquisas em História Indígena (GPHIAL). E-mail: adelsonlopes@uneal.edu.br

${ }^{2}$ Indígena Xucuru-Kariri de Palmeira dos Índios - pertencente à Aldeia Serra do Amaro. Doutoranda em Educação (Universidade Federal de Alagoas - UFAL). E-mail: larissa.ferro@cedu.ufal.br
} 


\section{Introdução: museu Xucurus de história, arte e costumes}

Este texto busca evidenciar os aspectos que constituem a história de formação do Museu Xucurus de História, Arte e Costumes, localizado no município alagoano de Palmeira dos Índios, destacando os silêncios da exposição e as múltiplas vozes dos sujeitos ali representados. Apresentamos aqui os frutos de uma pesquisa coletiva, desenvolvida no ano de 2019, porém respaldada em nossas ações enquanto membros do Grupo de Pesquisas da História Indígena de Alagoas - GPHIAL que tem se debruçado sobre os contextos vividos pelos povos indígenas nesse Estado.

Nossa ação foi direcionada para o museu por causa de vários atos públicos realizados pela sociedade civil e por alguns representantes dos indígenas Xukuru-Kariri que defendem a permanência do museu na antiga sede da Igreja Nossa Senhora do Rosário, em contraponto à administração pública municipal, que anunciou a transferência do acervo para outro espaço e a consequente devolução do prédio da igreja à Diocese. Tais disputas moldaram o olhar do pesquisador indigenista e da indígena que tem sua ancestralidade presente e exposta naquele espaço na constituição do presente texto.

Localizado no centro da cidade de Palmeira dos Índios-AL, o Museu Xucurus faz parte, com a praça que o abriga, do conjunto de atrações turísticas do lugar. A estrutura física desse museu é constituída por uma nave principal e duas naves laterais, as quais abrigam, respectivamente, a arte sacra católica e os artefatos que retratam os usos e costumes do não-índio, as porcelanas e os baús, enquanto em um anexo, aos fundos do prédio, ficam os elementos da cultura indígena e negra.

Foi na perspectiva da organização de um espaço de articulação de identidades locais e de guarda de artefatos que se associam às lembranças e esquecimentos individuais e coletivos, que foi criado o Museu Xucurus de História, Arte e Costumes, na cidade de Palmeira dos Índios, interior de Alagoas, em 1971. Seus fundadores foram o bispo Dom Otávio Aguiar, $1^{\circ}$ Bispo da diocese de Palmeira dos Índios, o comerciante e escritor Luiz B. Torres (idealizador do projeto) e o tenente Alberto de Oliveira Melo.

Apesar de a proposta inicial apontar para um espaço onde as identidades locais tivessem voz, o povo Xukuru-Kariri, que empresta seu etnômio para nominar o museu, é silenciado na gestão e na definição dos espaços de exposição. Os acervos possibilitam uma gama de sentidos e significados, uma polifonia de interpretações, porém emudecem as vozes dos sujeitos que têm suas identidades expostas.

Quem visita o Museu Xucurus orienta-se apenas por setas de indicação da sequência dos objetos e por poucas informações constantes em pequenos cartões de papel, afixados ao lado das peças que compõem o seu variado acervo. Não se observa a presença de pessoas com formação específica para desempenhar as funções de guia, recepcionar o turista ou cuidar tecnicamente do acervo; os poucos funcionários que ali trabalham são cedidos pela Prefeitura para controlar a entrada, vender os 
ingressos, seguir os visitantes durante a visita e colher suas assinaturas à saída.

Já em um primeiro olhar é nítido que o local abriga um acervo muito rico e variado, que incita várias interpretações, mas não dialoga com o público. As peças estão expostas sem obedecer a um projeto expográfico e dentre os funcionários não há quem explique com profundidade a história ou o contexto em que foi produzida a peça ou o conjunto ali exposto. Não há preocupação visível em estabelecer a relação do passado com o presente e o conjunto não se configura como espaço de negociações identitárias, apesar de, ao longo da história do município, seus gestores tentaram converter o espaço em ponto turístico.

Várias fotografias foram produzidas, em diferentes contextos, da Praça e da Igreja do Rosário que abriga o Museu Xucurus. São imagens que circulam em sites, jornais, blogs e redes sociais, a exemplo da foto da festividade de inauguração do Museu, ocasião em que o prédio recebeu uma pintura interna e externa, custeada por comerciantes do seu entorno. Tal fotografia é usada em panfletos e folders que apresentam Palmeira dos Índios como berço da cultura e do progresso, condição fomentada com uma locomotiva colocada na praça em frente à igreja, doada pela Usina Capricho, considerada a mais antiga do Estado de Alagoas.

\section{Igreja do Rosário dos Pretos, Museu Xucurus: a oficialização da negação}

No centro de Palmeira dos Índios, situa-se a Praça Minervo Fernandes Pimentel, localizada a aproximadamente 500 metros da Catedral Diocesana de Nossa Senhora do Amparo. Tal praça abriga a Igreja de Nossa Senhora do Rosário, construída de 1803 a 1805 com mão de obra de negros escravizados - que a utilizavam enquanto espaço de devoção ${ }^{3}$ - e sagrada como capela em 1880. Entre 1903 a 1917 o vigário João Guimarães Lessa assumiu o controle da Paróquia e, nela, fundou a Escola Nossa Senhora do Amparo, transferindo-a posteriormente para a Igreja Nossa Senhora do Amparo (atual Catedral) e, depois, para o Abrigo de São Vicente de Paulo (atual Colégio Diocesano Sagrada Família).

A imagem a seguir ${ }^{4}$ apresenta a localização do museu, da praça e da Catedral Diocesana, destacando a sua proximidade com a Praça da Independência, principal logradouro da cidade, onde fica situado o prédio da prefeitura municipal, espaço que fomentou o conflito sobre o uso do prédio que abriga o museu.

\footnotetext{
${ }^{3}$ Livro do Tombo da Diocese de Palmeira dos Índios (12/12/1971).

4 A imagem compõe a dissertação de mestrado em Arquitetura e Urbanismo: Dinâmicas do Espaço Habitado, de João Paulo Omena Silva, intitulada Entre o soar dos sinos e o apito do trem: modos de pensar o Museu Xucurus de Palmeira dos Índios/AL, apresentada em 2017 ao Programa de Pós-Graduação em Arquitetura e Urbanismo da Faculdade de Arquitetura e Urbanismo de Maceió
} 
Figura 1: Planta da Cidade

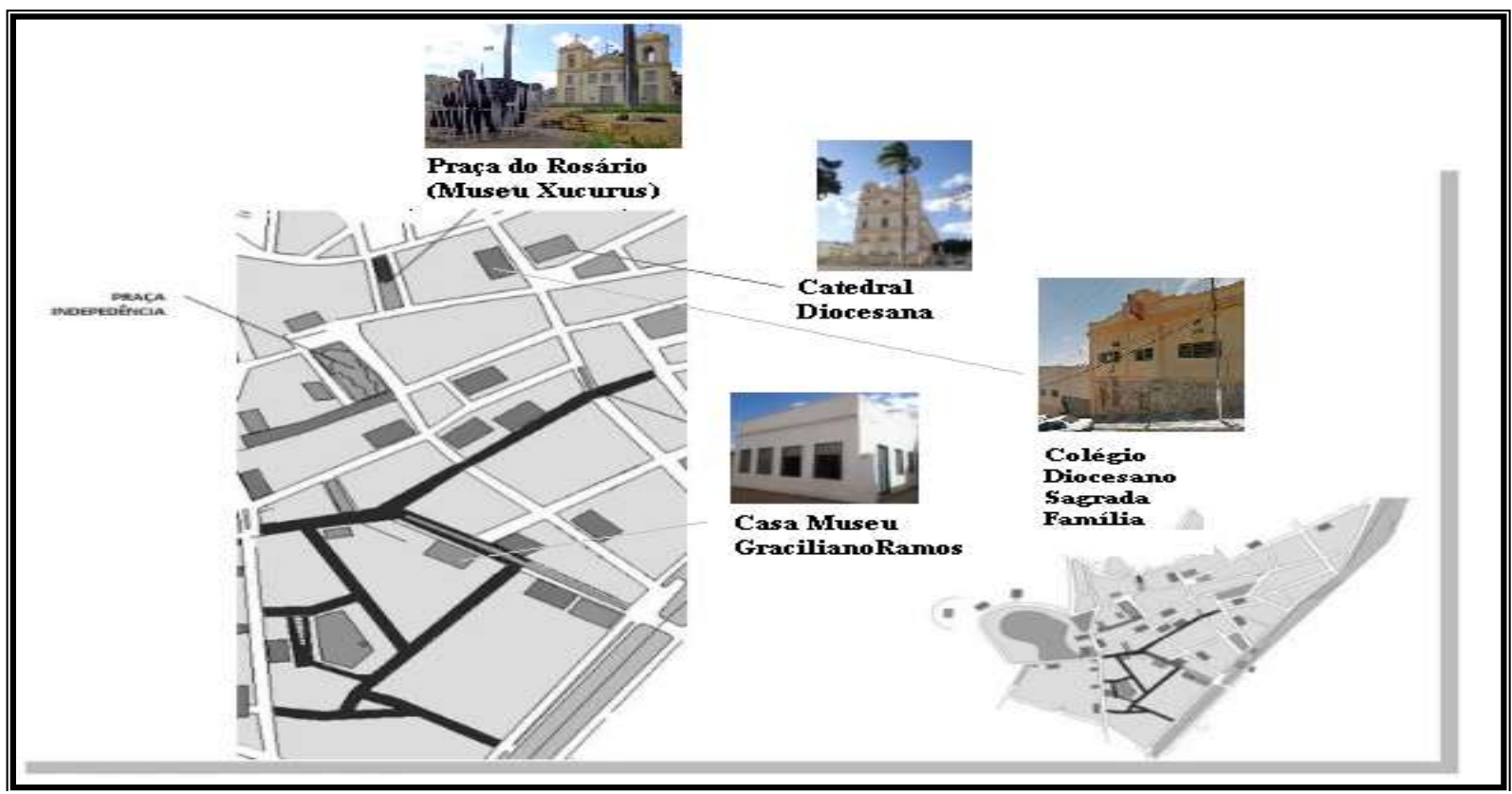

Fonte: Adaptado de Silva, 2017.

O comerciante Luiz Torres, entusiasta da história local e autor de várias obras sobre o lugar, dedicou-se a explorar o território e nas suas andanças encontrou (06) seis cemitérios indígenas e neles desenterrou algumas igaçabas (urnas funerárias indígenas), fato que atraiu pesquisadores como Estevão Pinto e Clóvis Antunes - esses estudiosos também desenterraram igaçabas. Conforme o próprio Luiz Torres, no seu livro "A terra de Tilixi e Tixiliá", foram retiradas 35 igaçabas dos cemitérios indígenas do município. Esses achados desencadearam, em Luiz Torres, o desejo de criar um espaço para exposição permanente dos achados e de artefatos e documentos da história da região. Em 1965, empolgado com a ideia, o comerciante procurou Dom Otávio Barbosa de Aguiar (Bispo Diocesano) e Alberto Oliveira (funcionário da Marinha do Brasil) e lhes disse que pretendia edificar um Museu de História em Palmeira dos Índios 5 . Sensibilizando os amigos, iniciou-se, então, o trabalho de criação do museu.

A iniciativa, porém, esbarrou em algumas dificuldades: a primeira, a definição de um local viável e que não gerasse custos; a segunda, era definir um acervo e conseguir o maior número possível de peças e artefatos (inclusive decidir se seria um museu sacro, histórico ou indígena); e a terceira dizia respeito à manutenção. O problema inicial foi superado pelo bispo que decidiu desativar a igreja, alegando a sua proximidade com a catedral, que passaria a abrigar os fieis da Igreja do Rosário.

Quanto ao segundo desafio, foi o mais fácil de ser vencido, pois a decisão foi criar um museu com temática variada desde artes e costumes

\footnotetext{
${ }^{5}$ As informações sobre o processo de criação do Museu foram colhidas de manuscritos de Luiz Torres que fazem parte do acervo do Grupo de Pesquisas da História Indígena de Alagoas - GPHIAL - em texto não publicado.
} 
a artefatos da história local, pois com essa abrangência qualquer objeto teria lugar. A participação do Bispo na empreitada foi salutar porque a Diocese de Palmeira dos Índios envolveu todos os seus párocos no processo de coleta de objetos com os fiéis. Isso se transformou numa grande campanha na região.

O terceiro impeditivo foi solucionado através de parcerias com o Governo do Estado de Alagoas - que assumiu a responsabilidade de ceder o pessoal administrativo - e a Prefeitura Municipal - que cedeu o pessoal da manutenção. Em 12 de Dezembro de 1971, na presença do professor Jaime d'Altavila - Secretário de Educação de Alagoas -, autoridades civis e religiosas municipais, o Museu foi oficialmente inaugurado e aberto à visitação pública, recebendo o nome de "Museu Xucurus de História, Artes e Costumes". Porém na placa colocada acima da porta de entrada consta apenas o nome "Museu Xucurus".

Fotografia 1: Igreja Nossa Senhora do Rosário (1951)

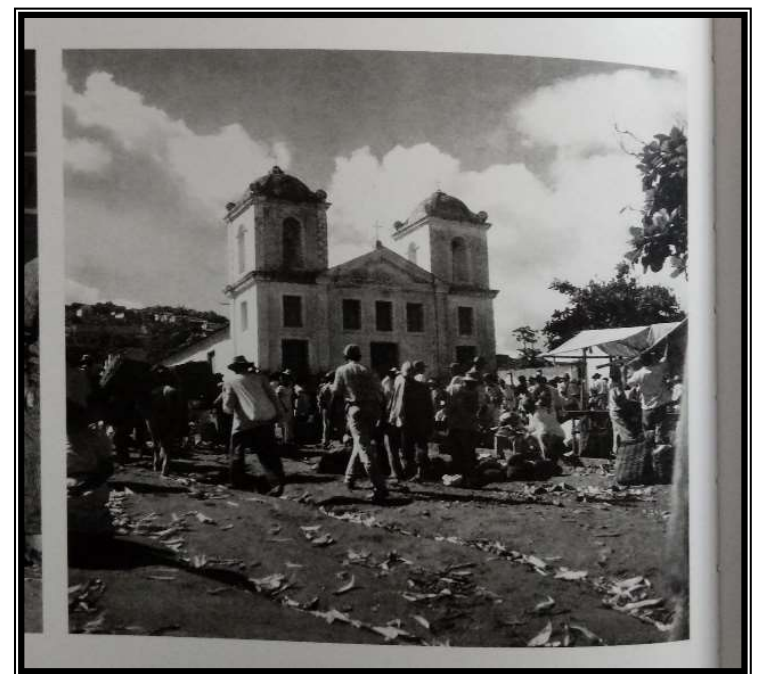

Fonte: Alagoas de Pierre Fatumbi Verger (2010)

Fotografia 2: Igreja Nossa Senhora do Rosário

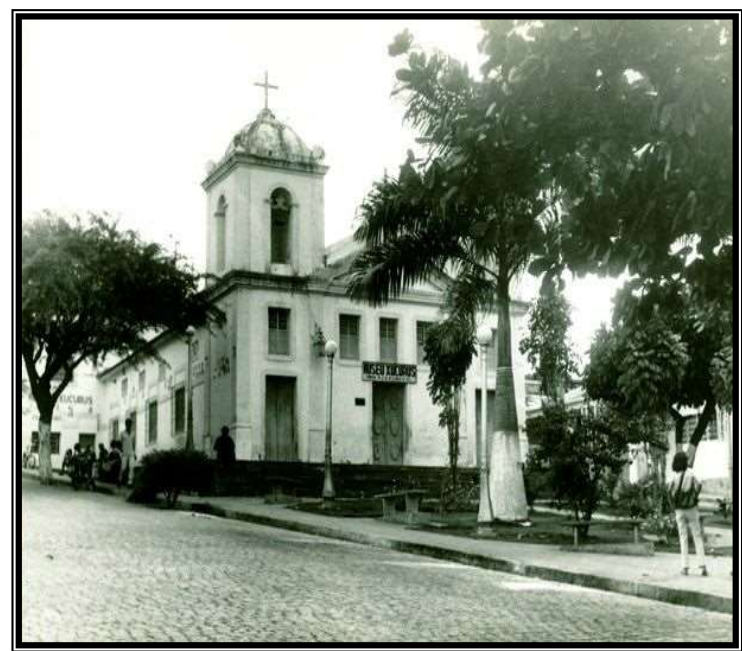

Fonte: IBGE (1959) 
Fotografia 3: Museu Xucurus

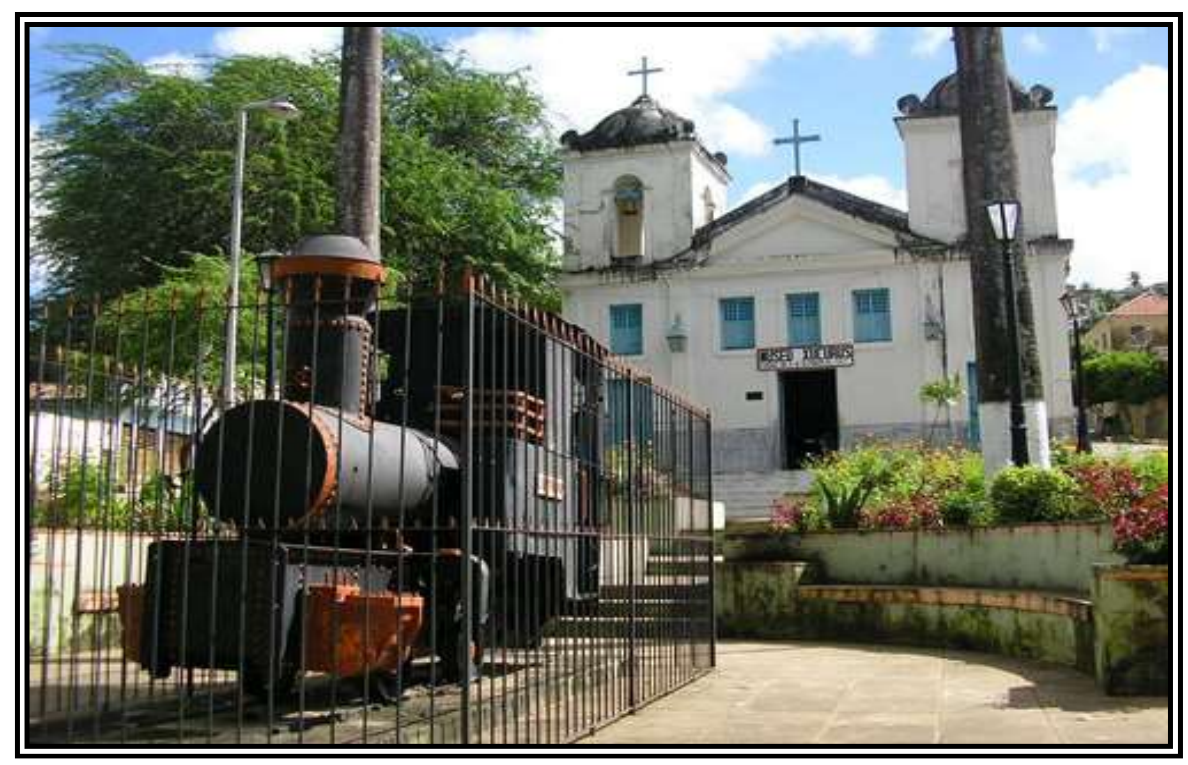

Fonte: Acervo GPHIAL ${ }^{6}$

Uma ala inaugurada em 09/09/1979, após a ampliação e reforma do prédio, foi dedicada aos usos e costumes do povo indígena XukuruKariri, abrigando as urnas funerárias (igaçabas), armas de madeira (como arco, flecha e tacape), ferramentas de pedra (machados e marretas), roupas de caroá usadas no ritual religioso denominado de Ouricuri e artesanato indígena: cocás, colares, pulseiras de madeira, sementes e ossos. Essa ala foi sendo deslocada, com o passar dos anos, saindo da parte principal da capela e sendo alocada no anexo, aos fundos do referido prédio.

Observa-se que, apesar do nome "Xucurus" constante na placa afixada sobre a porta principal do prédio, a temática indígena não ocupa papel central na exposição. Como exemplo, destacamos que as vestes expostas no museu recebem cuidados diferentes, sendo as roupas dos sacerdotes católicos protegidas em vitrines de vidro enquanto as roupas do ritual indígena ficam vestidas em manequins de fibra, sem nenhum cuidado ou proteção. Também sem cuidados, naquele local existe uma igaçaba com ossos indígenas expostos. Segundo um funcionário que guia as visitas: "essa urna aberta provoca um desgaste dos ossos que tendem a se decompor em poucos anos, a mesma coisa acontecerá com as palhas e fibras das vestes"”. As fotografias a seguir têm a função de melhor descrever o tratamento dado ao acervo e às diferenças entre as formas de exposição de vestes religiosas de indígenas e de sacerdotes católicos.

\footnotetext{
${ }^{6}$ GPHIAL - Grupo de Pesquisas em História Indígena de Alagoas, sediado no Campus III da Universidade Estadual de Alagoas, em Palmeira dos Índios. Ver: www.gphial-uneal.com.br

${ }^{7}$ Informação verbal do guia que preferiu não ser identificado, para evitar problemas com a administração do Museu (14/08/2019).
} 
Espaço Ameríndio

Fotografia 4: Vestes ritualísticas indígenas

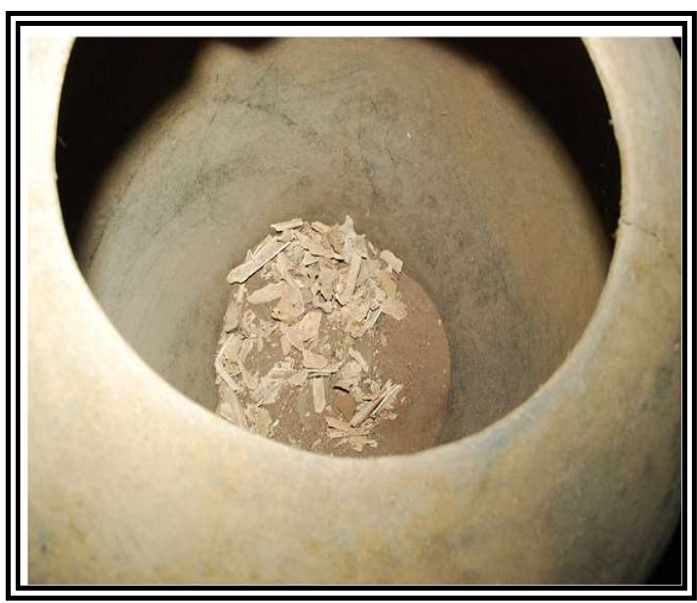

Fonte: Acervo pessoal dos autores, 2019
Fotografia 5: Igaçaba com ossos humanos

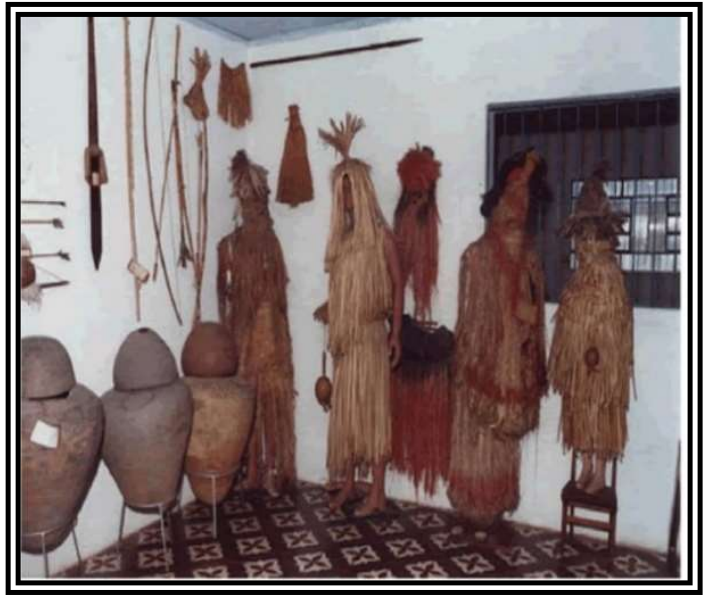

Fonte: Acervo pessoal dos autores, 2019

Fotografia 6: Vestes dos sacerdotes católicos

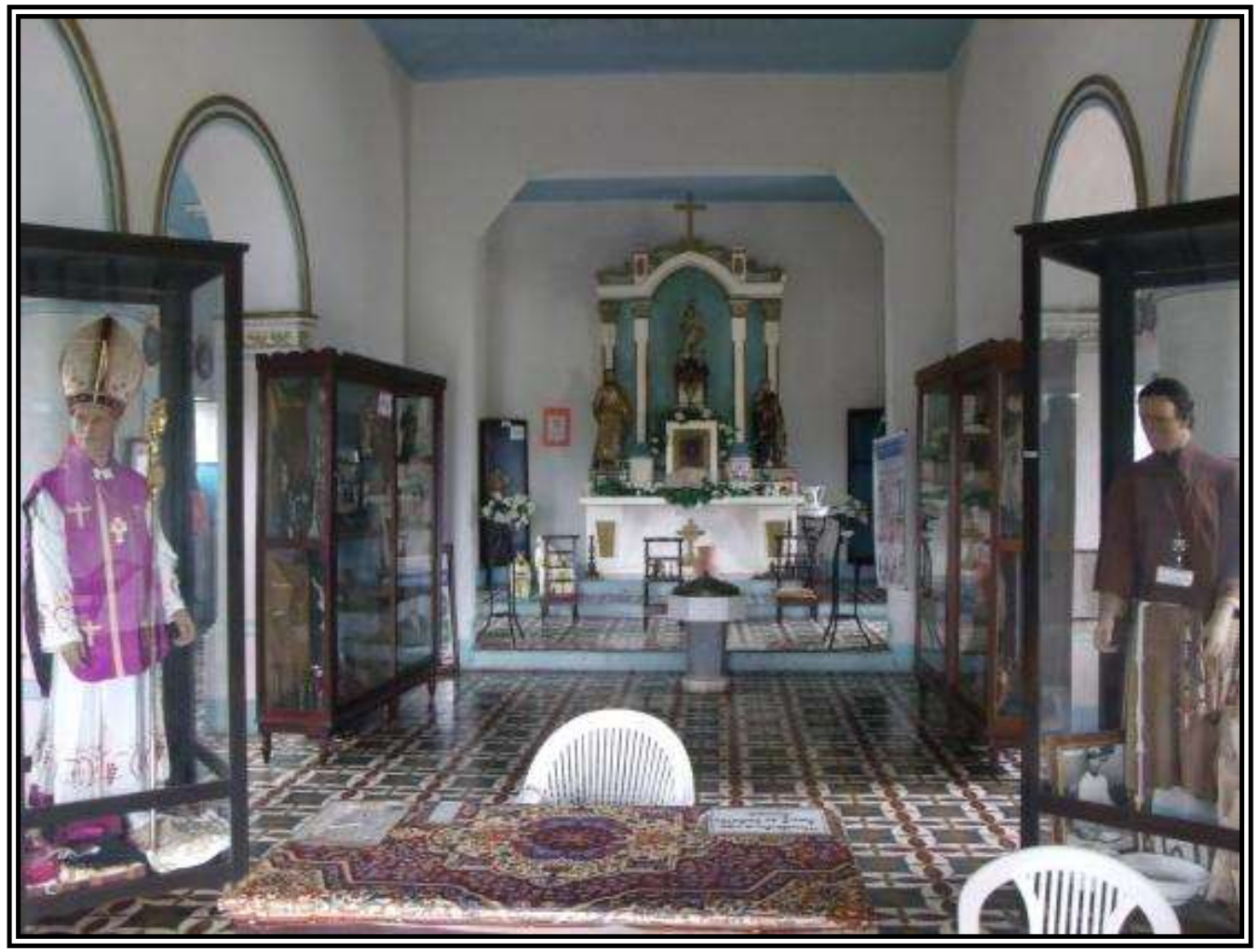

Fonte: Acervo pessoal dos autores, 2019

Tratamento semelhante é dado aos construtores da igreja, pois a exposição sobre a história da cultura negra se resume a manequins (também expostos nos fundos do museu) presos aos ferros que foram usados à época da escravidão - um deles traz uma placa de metal presa ao peito com a seguinte inscrição: "fujão e ladrão". Observa-se, com isso, 
que a transformação da igreja em museu oficializou a negação aos negros e indígenas naquele acervo museal.

Criado com a intenção de ser um espaço de diálogo entre as memórias e identidades locais, a instituição foi ganhando forma e aos poucos se tornou cartão postal da cidade. Quanto a sua organização, em 1973 foi criada a Sociedade Museu Xucurus composta por várias personagens da sociedade palmeirindiense ${ }^{8}$, dentre eles, os três pioneiros da criação do museu. O presidente da sociedade, conforme seu estatuto, seria sempre o bispo que estivesse no comando da Diocese de Palmeira dos Índios, demonstrando que mesmo desativada as marcas da função original permaneciam.

No artigo $1^{\circ}$ o Estatuto da Sociedade Museu Xucurus afirma que o "Museu Xucurus é uma sociedade civil, sem fins lucrativos" e sua manutenção caberia aos seus sócios beneficentes que voluntariamente se cadastravam como sócios efetivos, contribuintes, beneméritos ou correspondentes. Quanto à estrutura administrativa, o estatuto define gestão de 04 anos, sem remuneração, com uma diretoria composta por presidente, vice-presidente, 02 secretários, 02 tesoureiros e 01 diretor técnico, além de três Comissões (História, Geografia e Artes e Costumes ${ }^{9}$ ). $\mathrm{Na}$ atualidade, a Sociedade já não existe e a população assiste a um conflito sobre a veiculação de uma decisão, tomada pelo atual prefeito, de transferência do museu para outra localidade. Cabe destacar que o Artigo 53 da já citada Sociedade preconiza que em caso de sua extinção, o "[...] seu patrimônio passará a pertencer ao Centro Social Diocesano e, em segundo lugar, ao município de Palmeira dos Índios, sob condição de mantê-lo". Aí está a base para uma profunda discussão legal.

Nos últimos anos, o museu vem sendo alvo de olhares diversos, de silêncios administrativos, descuido com o acervo e exclusão com os sujeitos que são objeto das exposições. O último ato positivo registrado para dar visibilidade e dinamização na organização daquele espaço foi em 2007, quando ocorreu o cadastro no Sistema Nacional de Museus e a prefeitura realizou uma reforma no entorno, incluindo a pintura do prédio, jardinagem e iluminação. Porém, passados poucos anos, com a mudança de prefeito, o museu foi sendo relegado ao abandono, situação que culminou com uma petição assinada por uma desembargadora pedindo o retorno da igreja à sua condição inicial.

A petição gerou alguns comentários na cidade, dividiu opiniões, pois apareceram aqueles que defenderam a ideia por considerar que as autoridades políticas e eclesiásticas devem acatar o pedido da desembargadora ${ }^{10}$ e tomar as providências necessárias para a retirada do acervo da Igreja e, em ato contínuo, a sua reabertura como centro de oração. Na ocasião, o recém empossado bispo diocesano D. Dulcênio de

\footnotetext{
${ }^{8}$ Usamos esse termo para diferenciar o cidadão, habitante do município, dos torcedores do time de futebol Palmeiras.

${ }^{9}$ Ata da Assembleia de fundação da Sociedade Museu Xucurus, 1973, p.01

$10 \mathrm{https}$ ://minutopalmeiradosindios.cadaminuto.com.br/noticia/222/2012/02/11/em-palmeira-dos-indiosuma-igreja-serve-de-museu
} 
Matos decidiu que o templo deveria ser incorporado à Diocese e que a igreja retornasse às suas atividades religiosas, mas concluiu seu mandato sem fazer encaminhamentos nesse sentido. Quanto ao prefeito da época, cumpriu dois mandatos consecutivos e não tomou providências. $O$ assunto foi sendo esquecido até que a atual gestão municipal retomou a discussão.

A questão voltou a ser central em Palmeira dos Índios no primeiro semestre de 2019 quando foi divulgado, na imprensa local e em redes sociais, que a Prefeitura estava negociando a locação de um casarão, denominado Solar dos Leite, para abrigar o Museu. O casarão é um imóvel histórico, próximo da casa que foi habitada por Graciliano Ramos, porém a transferência do Museu implicaria várias questões de ordem prática, tais como:

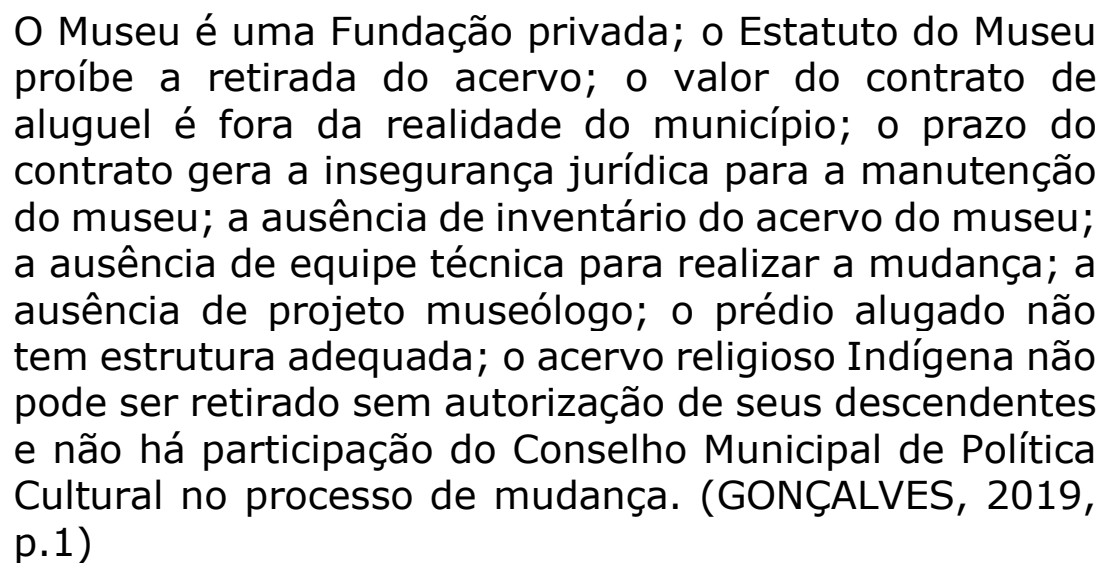

Além dessas questões, deve-se considerar a estrutura física do imóvel, pois a sua construção é do século XIX, bem como a questão do período da locação. São muitos os quesitos que necessitam de discussões amplas, com vários setores da sociedade, inclusive com a participação do Conselho de Cultura existente no município.

Criado o impasse e alegando falta de comunicação, o Jornal Tribuna do Sertão divulgou a notícia sobre o imbróglio, no dia 23/07/2019, com a seguinte manchete: Justiça concede liminar $e$ suspende mudança do Museu Xucurus. A matéria, assinada pelo jornalista Roberto Gonçalves, informava que o Juiz da $1^{\text {a }}$ vara da comarca de Palmeira dos índios havia expedido liminar suspendendo a transferência do acervo em atendimento à ação popular ingressada pelo advogado Elias Henrique (presidente do Conselho de Cultura). Na liminar, o Juiz determinou a realização de uma audiência entre as partes. Porém, quando da sua realização, o representante do prefeito deixou claro que a ideia é de transferência mesmo. Em entrevista, o presidente do Conselho de Cultura evidenciou algumas etapas do processo desencadeado nas semanas que antecederam a audiência da ação popular e destacou a posição defendida pelo procurador do município. Segundo ele,

No dia 08 de agosto de 2019 o prefeito convocou a gente do conselho de cultura, um representante indígena e 
uma museóloga para tratar do assunto lá no gabinete dele, e aí ficou decidido que ele iria, pelo menos por enquanto, suspender a ideia de mudança do museu e formou uma comissão constituída por essas pessoas: por mim, pela museóloga, por pessoas ligadas à prefeitura e à diocese; essa comissão iria estudar o caso, analisar qual seria a melhor saída (...) após isso, acho que duas semanas depois, aconteceu a audiência lá no fórum, a audiência da ação popular. E na audiência a prefeitura, que estava representada pelo procurador do município, não mencionou, em nenhum momento, essa constituição da comissão para falar do museu. Pelo contrário: o procurador quis defender a saída do museu a qualquer custo. A conversa tida com o prefeito anteriormente não valeu de nada, praticamente, não teve nenhum alinhamento com o procurador na audiência (SANTOS FILHO $^{11}$, 2019, informação verbal).

Percebemos que há, entre os envolvidos no processo, uma série de posicionamentos divergentes e sem efetividade para uma tomada de decisão final sobre o destino do Museu. A partir da divulgação da notícia jornalística, vem se intensificando as ações contrárias à transferência. Porém, não tem circulado nenhuma nota oficial da prefeitura, mas apenas os comentários em blogs, jornais on-line e redes sociais com informações sobre a intenção de se criar um "corredor cultural" colocando em espaços próximos os dois museus existentes na cidade ${ }^{12}$. Entretando, em entrevista ao Jornal Tribuna do Sertão ${ }^{13}$, o prefeito ressaltou que:

Nós temos um grupo de trabalho, montado pela prefeitura, para trabalhar a questão do Museu Xucurus. Em nenhum momento falamos em transferir o Museu Xucurus. Em nenhum momento dissemos que vamos levar o Xucurus, museu, para outro lugar. Nós falamos em fazer $((\ldots))$ e ai eu contratei uma museóloga pra fazer um inventário do Museu Xucurus, o que é que tem ali dentro, registrar esse inventário e a gente vai tirar algumas peças, tipo, as armas e levar para um Museu de História, Costumes e Tradições de Palmeira. A comissão é quem vai dizer o que é que sai o que é que fica. $O$ município é quem está responsável pelo Museu. Não tem mais diretoria. Tem uma lei municipal, mas ninguém vai fazer nada de forma afobada, nem atropelando, nós estamos ouvindo, conversando com o conselho... para que a gente discuta o melhor caminho, diante da

\footnotetext{
${ }^{11}$ Entrevista realizada com o Presidente do Conselho Municipal de Cultura Elias Henrique dos Santos Filho, na Biblioteca municipal no município de Palmeira dos Índios 24/08/2019.

${ }^{12}$ A cidade possui dos Museus. O primeiro corresponde ao Museu Xucurus e o segundo à Casa Museu Graciliano Ramos.

${ }^{13} \mathrm{http}: / /$ www.tribunadosertao.com.br/2019/09/indigenas-protestam-no-museu-xucurus-pela-permanenciaacervo-na-igreja-rosario/
} 
intenção que nós temos, mas transferir museu, eu não sei de onde saiu isso, quem criou isso, transformaram isso numa pendenga, numa bandeira política e nossa posição é de prudência, é de ouvir a todos, mas de tomar as medidas que precisam ser tomadas. (SILVA, 2019, informação verbal ${ }^{14}$ )

Observamos que há um desencontro de discursos, pois a ação ajuizada contra a remoção do museu nasceu e tramitou na justiça sem que o município, através do seu setor jurídico, contestasse a afirmação. A fala do presidente do Conselho Municipal de Cultura destaca que o procurador defendeu a transferência. Por outro lado, a atual Secretária de Cultura deixou claro que há a intenção da transferência, mas atribuiu essa iniciativa ao bispo anterior, enquanto a imprensa coloca que foi ação de uma desembargadora. Sobre o seu protagonismo na questão, afirmou que

(...) não é da competência da secretaria de cultura, ela decidir isso aí, eu posso agregar ao grupo, eu posso me aliar ao grupo, tenho esse dever, não posso me esquivar, não posso me anular, mas cabe ao chefe maior, ao chefe de governo, ao senhor prefeito, em consonância com a diocese, tentar resolver isso. Porque agora nós estamos com um Bispo novo, cada Bispo que aqui vem, tem uma forma de pensar. O anterior havia solicitado da prefeitura a Igreja para que ela servisse de espaço para celebração de missas que se chama sacralização (que é você tornar ativa a igreja a partir do sacrário, você sacraliza, por ser assim a igreja pode voltar realmente a ser igreja) né? Mas isso não ficou decidido, não foi nada no papel, foi somente na oralidade. Agora, nós estamos com outra realidade, com um outro Bispo que assumiu e ainda não houve um feedback por parte do governo e por parte da diocese. Sabemos pelo seu estatuto que é a diocese que é dona do terreno, mas sabemos também o seguinte: que cabe ao município a tutela, né? De tomar conta, é o município que, através dos seus funcionários, faz com que as portas desse museu sejam abertas de segunda a segunda, feriados e tudo mais. (MARQUES ${ }^{15}, 2019$ )

A fala da secretária não deixa dúvidas sobre a existência da ideia de transferência do Museu para outro espaço, mas não fez nenhuma consideração sobre os encaminhamentos ou planejamentos realizados pela sua secretaria em atendimento à decisão final dessa contenda. Convém destacar que esse museu não é temático, apesar de ter sido

\footnotetext{
${ }^{14}$ Áudio da entrevista concedida pelo Prefeito Júlio Cezar da Silva ao Jornal Tribuna do Sertão. Disponível em: $\quad$ http://www.tribunadosertao.com.br/2019/09/indigenas-protestam-no-museu-xucurus-pelapermanencia-acervo-na-igreja-rosario/

15 A Secretária Municipal de Cultura Isvânia Marques foi entrevistada em 11.09.2019. Pediu que as perguntas fossem escritas e enviou as respostas através do aplicativo WhatsApp.
} 
construído por negros e ter um nome indígena na placa que o nomeia, mas apenas os indígenas Xukuru-Kariri entre os sujeitos ali identificados se mobilizam, em ato público realizado no museu no dia 15/09/2019, pela manutenção da exposição na Igreja do Rosário.

Entrevistado sobre a polêmica da transferência, o Cacique Manoel Selestino ${ }^{16}$, da Aldeia Indígena Serra do Capela descreveu a história das escavações realizadas por Luiz Torres, Clóvis Antunes e Estevão Pinto e a posterior criação do museu, destacou a importância da exposição permanente de elementos da cultura indígena, mas não foi contundente quanto ao uso do prédio da igreja ou qualquer outro espaço na cidade. Foi muito firme na exposição do seu pensamento ao pedir que não deixem o museu acabar:

Agora, peço as autoridades que respeite a história de Palmeira dos Índios, a história viva da população de Palmeira dos Índios. Nós temos uma Palmeira frondosa que transformamos ela numa população de mais de 60 mil pessoas, nunca guerreamos com eles, agora quero o apoio deles, das autoridades e da justiça, para o museu não se acabar porque não se pode acabar uma história viva de um povo palmeirense, de um povo índio, de um povo áfrico-brasileiro (...) (SELESTINO, 2019).

Após fazer um relato sobre as lideranças indígenas que participaram do processo de escavações em Palmeira dos Índios, destacando a participação de membros da sua família, o cacique continuou seu relato apresentando um desejo de ter um espaço de memória na sua própria aldeia. O indígena demonstrou insatisfação com a exposição da cultura indígena no museu da cidade, questionou a falta de fotografias das lideranças do tronco formador dos Xukuru-Kariri e a inexistência de uma estante com estudos e/ou publicações sobre seu povo. Ainda questionou o sentido e "o lugar 'adequado' de muitos objetos que estão nos museus" (CLIFFORD, 1994, p. 88). Com um tom de voz bastante sério, na companhia do seu filho, Purinã Selestino, acrescentou:

quero dizer mais, que esse museu seja transferido para a pedra fundamental da criação do direito dos povos indígenas em Palmeira dos índios, que é a Aldeia Indígena Mãe Serra do Capela; as autoridades se querem ter uma história viva, bote onde está. Onde foi criado a história do museu foi aqui na Serra do Capela que é a aldeia mãe indígena, Serra do Capela que criou Fazenda Canto, Mata da Cafurna e várias outras aldeia. Tudo foi semente daqui da aldeia mãe Serra do Capela. É isso que tenho a dizer. (IDEM)

\footnotetext{
${ }^{16}$ Entrevista realizada com o Cacique Manoel Selestino, na Aldeia Serra do Capela em 08/09/2019.
} 
Esse pensamento é corroborado por pesquisadores como o arquiteto João Paulo Omena Silva17, pesquisador sobre a arquitetura do museu, que ratifica a fala do senhor Manoel Selestino ao afirmar: "Eu sou a favor de se criar museu nas aldeias; quando a gente fala da museologia moderna e contemporânea já parte do conceito de museus de território que é justamente o que os indígenas vêm lutando. Então por que não a própria aldeia?" (SILVA, 2019).

Além da ideia de criar um museu indígena na sua aldeia, o cacique também apresentou outro desejo, o de ocupar a Serra do Goití, local que abriga a estátua do Cristo do Goití, ícone religioso e turístico de Palmeira dos Índios, porém situado no território que é disputado juridicamente entre indígenas e posseiros. Sobre tal espaço, enfatizou:

nós pretende ativar o museu, mas que seja dentro de nossa aldeia ou aqui. E agora é que nós devemos brigar. Sabe qual é a briga agora? Tomar de conta da Serra do Goití. Porque ali, negociaram dentro do patrimônio, ali foi uma invasão, foi uma invasão! Porque a terra foi delimitada pelo Juiz Federal dando a causa ganha e dando o parecer para a desintrusão do povo dentro do patrimônio indígena. Mas o prefeito agora invadiu, né? Ali é uma invasão, minha gente! (IDEM).

Tal relato evidencia o clima de tensão que circunda o cotidiano de Palmeira dos Índios, onde a tônica é a posse da terra, motivo do litígio entre indígenas e posseiros. O conflito territorial vem dividindo opiniões na região desde o século XIX e refletiu no museu, pois em alguns momentos teve a placa com o nome "Museu Xucurus" retirada da fachada do prédio, da mesma forma que o acervo indígena foi sendo movido da entrada da igreja para um anexo construído aos fundos. Por outro lado, existem aqueles que, além de defenderem a preservação do museu no prédio da igreja, ainda propõem a contratação de indígenas para atuarem como guias na ala específica sobre sua cultura. Sobre esse pensamento que circula em alguns espaços do município, a secretária de cultura falou que:

é importante também que no museu se fizesse presente a representação indígena, que o nativo lá estivesse explicando para o pessoal que vem visitar, para o turista, que especialmente fossem eles a falar sobre a igaçaba, fossem eles a falar sobre 0 toré ${ }^{18}$, fossem eles a falar

\footnotetext{
${ }^{17}$ Entrevista realizada com o arquiteto João Paulo Omena Silva em 10/09/2019.

$18 \mathrm{O}$ toré é uma dança circular, praticada pelos indígenas do Nordeste. Caracteriza-se pela entoação de cantos, pela dança em pares e pela batida forte do pé no chão. Com a perda da língua nativa, converteu-se no principal elemento de identificação étnica. Apesar de ser um bailado performático muito agradável ao olhar externo, é também elemento de salutar importância na configuração ritualística dos referidos indígenas. O seu significado vai além de uma dança que expõe a identidade indígena de um povo: demarca fronteiras entre índios e não índios, representa resistência, ressurgência e força. No toré, estão ecoadas as vozes da coletividade indígena que se manteve viva e presente, mesmo diante de um cenário de extermínio, perseguições ou negação identitária.
} 
sobre os seus ritos, seus costumes, suas tradições, nada melhor que os nativos para explicar assim, por mais que saibam os outros que lá estão (MARQUES, 2019).

Afirmar que o museu é um espaço de múltiplos olhares, de múltiplas interpretações, é também afirmar que o seu papel é muito diverso, pois na mesma medida que expõe, silencia os povos tradicionais. A forma como a exposição é organizada se constitui no que chamamos de polifonias dos olhares sobre os sujeitos e isso é fruto do olhar ou das concepções que o visitante tem sobre o povo ali representado. Pode-se afirmar que se trata de um "gabinete de curiosidades" (SILVA e GORDON, 2005).

A exposição, na forma como é organizada, não incita reflexões mais criticas sobre os lugares sociais dos sujeitos ali retratados, mas obedece a uma hierarquia categorizada pelo olhar de quem a organizou. Dessa forma, há uma necessidade urgente de espacializar o espaço de exposição do acervo, constituído por:

nave principal e duas naves laterais. Na nave principal tem a arte sacra católica, nas naves laterais tem os usos e costumes do branco, as porcelanas, os baús e, em cima, no anexo, os elementos da cultura do índio e do negro. Quando eu espacializei isso, comecei a perceber os valores atribuídos. (...) a gente tem uma igreja construída por negros, que não era uma igreja de negros, era uma igreja católica, a gente vai ter um museu que leva um nome indígena, de uma etnia, mas o museu não é um museu temático, somente indígena, e mesmo assim essa etnia é colocada de uma maneira bem exótica naquele acervo é bem estereotipado, né isso? (...) Daí, eu dividi em dez categorias o acervo (...). A primeira categoria eu denominei de formação histórica, relatei os três fundadores do museu, do outro lado uma cruz que a Sesmaria colocou lá; você tem a visão do branco, a visão elitista, cadê o negro na porta? Cadê o índio? Aí eu fui adentrando. Arte sacra, católica. Mas se foi uma igreja construída pelos negros, tem a questão que o negro não poderia cultuar a sua religião aqui e aí tem os sincretismos. Enquanto que ele tava alí cultuando a Nossa Senhora do Rosário, para os brancos, na verdade ele tava cultuando Iemanjá. E eu fui descendo, subindo, fazendo essas análises. (SILVA, 2019).

Este relato de João Paulo Omena Silva é resultante do seu olhar como pesquisador, fruto de inúmeras visitas àquele espaço, quando realizou entrevistas com vários moradores, frequentadores e funcionários do museu, para realização da sua escrita de dissertação. Percebe-se uma ótica envolvida com a questão funcional associada à concepção que ele tem sobre os povos ali retratados. Ótica diferente da apresentada em rede 
social, na postagem de uma jornalista local sobre o ato realizado por indígenas que reivindicavam a permanência do acervo no museu.

Fotografia 7: Resistência Indígena contra a transferência do museu

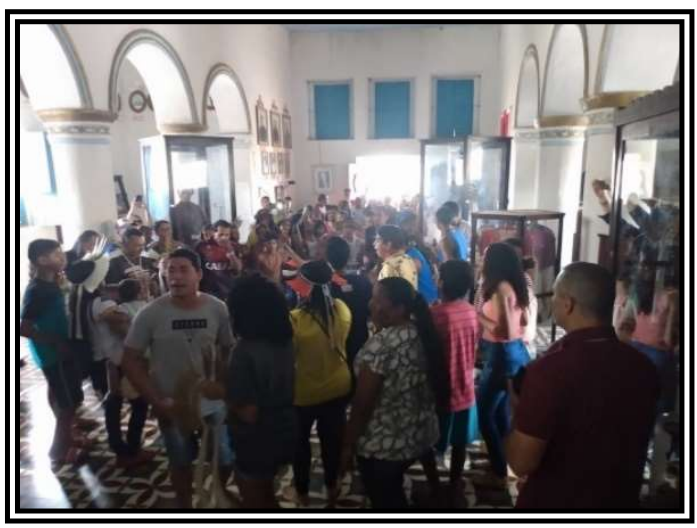

Fonte: Acervo pessoal dos autores, 2019
Fotografia 8: Resistência Indígena contra a transferência do museu

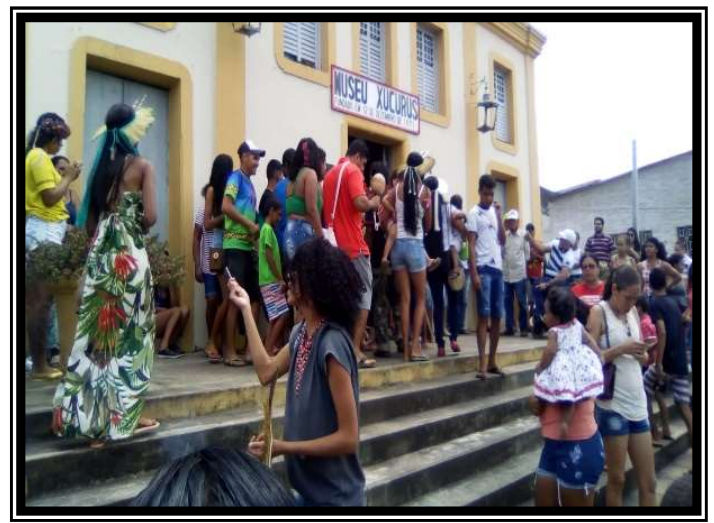

Fonte: Acervo pessoal dos autores, 2019

Na postagem de 14/09/2019 às $14 \mathrm{~h}$ e $49 \mathrm{~min}$, a referida jornalista colocou: Festa pagã na Igreja? Falta de respeito! Abaixo dessa postagem, foi colocado um vídeo com os indígenas dançando o Toré no salão principal do museu, a nave principal da igreja. Logo abaixo do vídeo, a desembargadora, que sugeriu a devolução da igreja à diocese, postou o seguinte comentário: "Olhem a falta de respeito desses falsos Índios dançando Toré bem em frente ao Sacrário e à imagem de Nossa Senhora do Rosário! 14 de setembro às $11 \mathrm{~h}$. 48min. Absurdo! Profanação ao Templo Sagrado de Deus!" Um elemento deve ser considerado para compreender o contexto: esse comentário antecede, em horas, o comentário da jornalista, o que nos leva a inferir que a jornalista compartilhou a postagem. Após esse, aparece mais um comentário: "instigados por quem não tem o que fazer... Jesus Cristo tem uns inquilinos que não valem nem a vida que tem".

Diante das questões expostas, observamos o quanto os discursos tendem a ser o reflexo das formações e concepções individuais de quem os externam. No caso onde aparece a crítica à dança do Toré na igreja, faz-se necessário refletir sobre o conceito que a magistrada possui a respeito de religião, sincretismo e tolerância, pois coloca o Toré (símbolo da indianidade no Nordeste e elo entre o humano e o sagrado) como menor e desrespeitoso. Essa visão tem sido típica no Brasil onde religiões indígenas, ciganas e de matriz africana são alvos de preconceito, perseguição e descrédito. Isso é fruto da intolerância imposta pelos colonizadores, silenciada durante certo período e externada amplamente no atual contexto político do país.

Outros olhares, outras polifonias do museu são as formas como os indígenas se percebem no acervo. Há aqueles mais entusiastas que se contentam com a referência ao nome da etnia na placa existente na 
fachada do prédio. Alguns reclamam da profanação dos cemitérios e almejam o retorno dos artefatos ao seu território original. Há os que defendem a contratação de um indígena para ser guia na ala específica sobre seu povo e reclamam a ampliação do acervo, conservando-o onde está desde a criação do museu e há aqueles que não se identificam com aquela exposição, alegando que ali a cultura está estática, morta e silenciada. Esses últimos dizem que ali é um museu dos outros e não se identificam nele.

A noção de "museu dos outros" é muito estranha. Ela remete precisamente aos que são definidos como "outros" em oposição a Nós. O "museu dos Outros" expõe as "coisas dos outros": objetos que tem por característica principal serem exó Dossiê Museus, auto-representação e agência indígenaticos no próprio sentido da palavra, ou seja, serem originários de um lugar distante e terem sido levados até "nossa terra" pelos que estiveram na "terra dos outros" por diversos motivos: expedições militares, missões religiosas, comércios, explorações, administração, viagem, etc. (DE L'ESTOILE, 2011, p. 36).

A noção de museu dos outros é apresentada em contraponto à noção de identificação ou pertencimento. Dessa forma, o "gabinete de curiosidades", apesar da sua importância, não dialoga especificamente com nenhuma cultura, povo, período ou tema específico. Associado a isso, a falta de cuidados com a estrutura física do prédio, a inexistência de um projeto de expografia e de pessoal especializado para o trabalho em museu, converte-o em um amontoado de peças, sem descrição aprofundada, caracterizando-se como obra de colecionador, muitas vezes informando apenas a origem e o nome do artefato.

\section{Conclusões: a polifonia da mediação}

Observando o variado acervo do Museu é perceptível o quanto os seus idealizadores se preocuparam em criar um espaço de memória onde os objetos que compõem o acervo servem como rótulo social para algumas das famílias que doaram objetos com a intenção de ver seus sobrenomes expostos nas vitrines, muitas vezes atribuindo a isso uma importância maior do que o histórico da peça.

O acervo é responsável pela criação de uma imagem sobre os sujeitos que formam a identidade de Palmeira dos Índios, porém não possui significação fora do seu contexto original, como é o caso dos marcos usados como limites das terras doadas pelo sesmeiro, em 1770, para criação de uma missão indígena sob os cuidados do Frei Domingos de São José (PEIXOTO, 2013) e das igaçabas que, fora do seu território original, perdem a função de comprovação dos limites territoriais e da ancestralidade indígena sobre tal território. 
Diante do contexto atual, quando um embate se desenvolve entre o Prefeito e o Conselho Municipal de Cultura sobre a mudança do acervo para outro prédio, locado para esse fim - gerando notícias nos jornais, postagens nas redes sociais, ações judiciais, mobilizações de indígenas e simpatizantes da causa e reações mais tímidas daqueles que defendem a divisão do acervo e criação de um novo museu -, cabe o questionamento sobre a eficiência da exposição dos artefatos indígenas e afro-brasileiros como produtores de visibilidade da cultura e da identidade local.

A forma como os artefatos são expostos gera questionamentos sobre a sua organização enquanto reflexo da imagem que os organizadores têm dos sujeitos e das culturas expostas naquele ambiente, principalmente em relação ao índio que é visto por parte da sociedade palmeirindiense como um ser folclórico, lendário e do passado.

O embate continua, as opiniões são divergentes sobre o futuro do museu, as peças expostas cumprem mais o papel de silenciar os sujeitos do que criar uma identidade ou promover a visibilidade do povo que a construiu ou da etnia que dá nome ao museu. A dicotomia igreja - museu é muito marcante e vem dividindo os grupos que estudam ou trabalham com cultura no município, da mesma forma que juristas, professores e pesquisadores divergem quanto ao destino do acervo.

Passaram-se dois séculos da criação do Museu Real e quase meio século da criação do Museu Xucurus, criados em contextos e situações diferentes, porém cada um com finalidade específica para seus criadores, com percepções particulares daqueles que visitaram seus acervos. Mas a principal singularidade está na forma como cada um dialoga com os sujeitos que produziram as peças que compõem suas exposições.

Esta pesquisa não consegue responder aos questionamentos sobre as polifonias nas interpretações das identidades descritas ou modeladas a partir do acervo museal. Mas esperamos, em um futuro muito próximo, poder apresentar a conclusão da disputa sobre o destino do acervo e, em um ato de maior otimismo, dizer que as coleções foram organizadas de maneira a fazer ecoar a voz dos sujeitos em polifonias que traduzam identidade, visibilidade e pertencimento. 
Espaço Ameríndio

\section{Referências bibliográficas}

ABREU, Regina. "Patrimônio Cultural: tensões e disputas no contexto de uma nova ordem discursiva". In: LIMA FILHO, Manuel; ECKERT, Cornélia; BELTRÃO, Jane (orgs.). Antropologia e Patrimônio Cultural - diálogos e desafios contemporâneos. Blumenau: Nova Letra, 2007.

AGUIAR, Dom Otávio. Palmeira dos Índios. 15 anos de Diocese. Indusgraf Indiana Ltda: 1977.

BARTH, Fredrik. "Etnicidade e o conceito de cultura". In: Antropolítica: Revista Contemporânea de Antropologia e Ciência Política, Niterói, n. 19, $2^{\text {o }}$ semestre. 2005.

BRASIL. Instituto Brasileiro de Geografia e Estatística - IBGE. Enciclopédia dos Municípios Brasileiros. Rio de Janeiro, IBGE, vol. XIX, 1959.

BOTELHO, A.; SCHWARCZ, L (org.). Antropologia dos objetos. Coleções, Museus, Patrimônios. Rio de Janeiro: 2007 (Coleção Museu, Memória e Cidadania).

CHAGAS, Mário (org.). Museus. Revista do Patrimônio Histórico e Artístico Nacional. No 31. Brasília: MinC, IPHAN, 2005.

CHAGAS, M. "Museu do Índio: Uma instituição singular e um problema universal". In: FILHO, M.F.L.; ECKERT, C.; BELTRÃO, J. (orgs). Antropologia e Patrimônio Cultural. Diálogos e Desafios Contemporâneos. Blumenau: Nova Letra, 2007,pp. 175198.

CLIFFORD, James. "Colecionando arte e cultura". Revista do Patrimônio Histórico e Artístico Nacional, $n^{\circ}$ 23. Rio de Janeiro, IPHAN, 1994, pp 68-89.

DANTAS, Cármen Lúcia \& BARADEL, Alex. Alagoas de Pierre Fatumbi Verger. Maceió: Caleidoscópio, 2010.

DE L'ESTOILE, Benoît. "O museu nacional como paradigma: reflexões sobre o Museu do Outro", em Magalhaes, Aline Montenegro, Bezerra, Rafael Zamorano. (Orgs.) Os museus nacionais e os desafios do contemporâneo. Rio de Janeiro: Museu Histórico Nacional.2011.

GOMES, Alexandre Oliveira. Aquilo é uma coisa de índio. Objetos, memória e etnicidade entre os Kanindé do Ceará. Dissertação (Mestrado em Antropologia) Programa de Pós-Graduação em Antropologia, Centro de Filosofia e Ciências Humanas (CFCH), da Universidade Federal de Pernambuco, Recife, 2012. 20

GONÇALVES, Roberto. Justiça concede liminar e suspende mudança do Museu Xucurús. In Cada Minuto. Disponível em: http://www.cadaminuto.com.br/notícia/342756/2019/07/23/justica-concede-liminar-esuspende-mudanca-do-museu-xucurus Acesso em 20/09/2019. 
Espaço Ameríndio

PEIXOTO, José Adelson Lopes. Memórias e Imagens em Confronto: Os XukuruKariri nos acervos de Luiz Torres e Lenoir Tibiriçá. João Pessoa: PPGA-UFPB, 2013. (Dissertação de Mestrado em Antropologia).

PESSANHA, José Américo da Motta. “O sentido dos museus na cultura”. In: O MUSEU em perspectiva. Rio de Janeiro: Ministério da Cultura/Funarte, (Série Encontros e Estudos 2). 1996.

QUEIROZ, Álvaro. Notas de História da Igreja em Alagoas. Maceió: EDUFAL, 2015 http://diocesedepalmeiradosindios.blogspot.com/p/historia.html

SCHWARCZ, Lilia Moritz. O espetáculo das raças. Cientistas, instituições a questão racial no Brasil 1870-1930. São Paulo: Companhia das Letras, 2008.

SCHWARCZ, Lilia Moritz; STARLING, Heloisa Murgel. Brasil: uma biografia. São Paulo: Companhia das Letras, 2015.

SILVA, Fabiana Andréia; GORDON, Cesar (orgs.). Fotografias de Wagner Souza e Silva. Xicrin: uma coleção etnográfica. São Paulo: Edusp, 2011.

SILVA, João Paulo Omena. Entre o soar dos sinos e o apito do trem: modos de pensar o Museu Xucurus de Palmeira dos Índios/AL. Maceio: Faculdade de Arquitetura e Urbanismo. Programa de Pós-Graduação em Arquitetura e Urbanismo. 2017. Dissertação (Mestrado em Arquitetura e Urbanismo: Dinâmicas do Espaço Habitado) 